\title{
1. Da violência divina ao estado de exceção benjaminiano
}

João C. Galvão Jr.*

Resumo. A proposta deste trabalho é abordar a "segunda natureza em excesso", onde a barbárie do poder soberano é contínua: assassinatos dos subalternos, membros dos movimentos sociais, "cidadãos" excluídos, sofrendo com a atuação mortífera da polícia política e legitimada por um sistema de justiça fascista. E rapidamente, as pessoas, simplesmente se contentam com o "retorno" à "normalidade", reflexo de uma "violência calada" que mantém uma sociedade burguesa naturalizando-a e retirando a capacidade de dizer não ao sistema; a separação brutal dos trabalhadores e da sua produção, feita por leis sanguinárias, a ferro e fogo, uma violência escondida que não é mais contestada pelo proletário. Porém, ainda existem os que não se subordinam ao "estatuto do proletário"; não calam esta violência, buscando uma vontade de vontade que se estabelece e desafia tudo o que está presente. Por isso, interpretar positivamente a violência divina benjaminiana (1921) numa perspectiva histórica, ou seja, junto com o real estado de exceção benjaminiano (1940), é tarefa de todo intelectual comprometido com as forças destrutivas da "segunda natureza em excesso", exatamente para possibilitar que esta cebola seja descascada e comida.

Palavras-chave. Força, violência, poder, lei, Estado de exceção.

\begin{abstract}
The purpose of this study is to address "second nature in excess", whereby barbaric of supreme power is continuing: the subordinated murdering, members of social movements, excluded "citizens", suffering with the action from the political police and legitimated by a fascist justice system. Rapidly, people simply content with the "return" of "normality", reflex of "silent violence" that maintains a bourgeoisie society removing the capacity to say no to the system; the brutal separation from workers and their production, based in bloody laws, a hidden violence which is not anymore contested by the proletarian. However, there are still the ones not subordinated to "proletarian statute"; whose do not unspeak this violence, searching for a will of will that establishes and confronts everything that is present. Therefore to interpret positively the Benjaminian divine violence (1921) on a historical perspective, that is, together with the Benjaminian real state of exception (1940), is a task for every intellectual committed with the destructive forces of the "second nature in excess", exactly for the possibility of peeling and eating this onion.
\end{abstract}

Key words: Strength, violence, power, law, State of exception.

* João C. Galvão Jr. é doutorando em Ciência Política na UFF - Instituto de Ciências Humanas e Filosofia 


\section{Da violência divina ao estado de exceção benjaminiano}

\section{Introdução}

$\mathrm{Na}$ "segunda natureza" em excesso a barbárie do poder soberano é contínua: assassinatos dos subalternos, membros dos movimentos sociais, "cidadãos" excluídos, sofrendo com a atuação mortífera da polícia política e legitimada por um sistema de justiça fascista. E rapidamente, as pessoas, simplesmente se contentam com o "retorno" à "normalidade", reflexo de uma "violência calada" que mantém uma sociedade burguesa naturalizando-a e retirando a capacidade de dizer não ao sistema, à separação brutal dos trabalhadores e da sua produção, feita por leis sanguinárias, a ferro e fogo, em uma violência escondida que não é mais contestada pelo proletário. A menos que esta cebola não seja devidamente descascada, alguns poderiam dizer que "o sonho acabou", visto que nem mesmo os que fazem parte do "capitalismo de periferia" são capazes de mover uma palha para dar um passo adiante, no temor de perderem "seus" direitos burgueses positivados ao longo da caminhada secular.

Porém, ainda existem aqueles que não se subordinam ao "estatuto do proletário", que sentem a força criativa do direito enquanto fenômeno político "como arte do impossível" que pulsa na rua, ou, dependendo da intensidade, na violência popular. Estes não calam esta violência numa contra violência, muito embora suas energias não sejam "revolucionárias"; buscando uma vontade de vontade que se estabelece e desafia tudo o que está presente; este desafio ocorre nos seres humanos e tem a expressão na obra de Walter Benjamin.

A preferência pelos fortes exige coragem, um movimento que desce aos "últimos escravizados", grande desafio de qualquer pensador que toma uma postura sem medo ante o terrível, dizendo sim à realidade; deixando de lado a vontade de verdade que esvazia o futuro, a vontade excessiva de conhecimento que esteriliza a vida, o excesso de história produzido pelo conhecimento científico que paralisa as forças criativas. O viver num mundo subalterno se apresenta como um jogo de forças políticas e sociais na afirmação diária de direito(s).

No sertão brasileiro, Euclydes da Cunha intuiu que estava nascendo ali uma nova forma de organização social; uma complexa formação de forças ativas em plena seca, onde o que era água era considerado por ele como manifestação da vida. Nos 
Sertões, referiu-se "às fortes tempestades que apagam o incêndio surdo das secas"; ${ }^{1}$ uma vontade de potência - "potência política" a romper com o contínuo histórico, da "velha" república brasileira, "produzindo verdadeiras avalanches que tudo destroem em sua passagem...", criticando fortemente este regime republicano: "o regime decorre num intermitir deplorável, que lembra um círculo vicioso de catástrofes"; ${ }^{2}$ do topo da Favela, Euclydes atenta-se para os "descampados", o que hoje em dia poderíamos chamar de "sem tetos" ou "sem terras", enquanto seu olhar fascinado perturbava-se no "desequilíbrio das camadas desigualmente aquecidas", ou seja, com energias de diferentes intensidades a fluírem por toda sociedade, algumas fortes, mas sem a proteção estatal e algumas fracas beneficiadas pela ordem "republicana". Nesse artificialismo "humano" as fracas energias vencem as fortes energias num jogo antidialético e covarde, construindo a história dos vencedores. Alertava-se pela primeira vez no Brasil da "absorção e defesa"” de uma "elevação", anônima na ciência, ignorada dos sábios e dos estrategistas estudiosos do artificialismo "humano"- força clandestina que defende e se dispersa nas massas; movimento clandestino que se auto-alimenta dos trabalhadores subalternos, conquista mentes e corações dos proletários, que "unem-se, intimamente abraçados, transmudando-se em plantas sociais", usadas como escudo; permanecendo invisíveis na sociedade subalterna, dentro da sociedade popular. Aquilo que o brasileiro Euclydes da Cunha comparou a uma "chapa incandescente de ardência inaturável", pois sim, são poucos na sociedade burguesa que tem o prazer de tocá-la, saboreá-la e sentir as sensações de suas potências elevadas a mil.

Será talvez relevante apontar que os estudos sobre esta forma de intensidade é um compromisso alargado com a questão da filosofia política da história, de tal forma que este posterior estudo pode ser visto como emergindo daquele questionar: no começo da lei há um certo fora-da-lei, um certo real da violência que coincide com o próprio ato de instauração da lei, a verdade última sobre o império da lei é a de uma usurpação, e todo o pensamento político filosófico clássico repousa num desmentido desse violento ato de fundação. Este é o hediondo momento fascista do pensamento burguês, o qual expõe a filosofia e a teoria política à violência através da tentativa de ligá-las a lei. Talvez seja por isso que às verdades da filosofia faltam a necessidade e a marca da

\footnotetext{
${ }^{1}$ CUNHA, E. R. P. Os Sertões - Campanha de Canudos, Brasília: UnB, 1963, p. 38.

${ }^{2}$ Idem, p. 52.

${ }^{3}$ Idem, p. 38.
} 
necessidade e às verdades da teoria política faltam conceitos que não sejam marcados pela violência da lei e do Estado.

Portanto, é preciso descer da solidão da montanha para confrontar a ignorância da sociedade burguesa - fascista. Pela mesma via, os "últimos escravizados", insurgentes, que não se ajoelham aos valores burgueses seculares - cristãos, tem mais força no corpo do que todos os "intelectuais" reunidos, estes, que desejam e amam as sombras do poder. Na medida em que são livres, os insurgentes desafiam a autoridade, constituindo uma força de resistência; a lembrança é de épocas fortes e povos vigorosos, que não flexionam acerca de seu(s) direito(s), dos princípios que fazem agir: a certeza instintiva na ação. Digno de pensamento é o estudo que une racionalismo e irracionalismo numa perspectiva dialética; o "não-humano" é frequentemente entendido como animalidade, a qual não é a base adequada para caracterizar o outro. Poderá alguém chamar "irracionalismo" à tentativa de nos acordar do sono, um conjunto de forças operando na "humanidade" dos seres humanos?

\section{Real da Violência}

A sociedade burguesa toma inúmeras precauções contra a violência ao passo que a educação é orientada para atenuar de tal modo nossas tendências à violência que somos naturalmente levados a pensar que todo ato de violência é uma manifestação de regressão à barbárie. A história do homem foi sempre violenta; viver em sociedade foi sempre um viver violento; a violência sempre presente aparece em suas várias faces. Nosso tempo está marcado pela violência, onipresente e multiforme nas suas variadas e distintas manifestações. O fenômeno da violência, em suas várias modalidades, passa a ocupar então um lugar privilegiado no pensamento político filosófico, não pretendendose chegar aqui ao estabelecimento de uma tipologia da violência; falta ainda um conceito preciso do que seja violência; porém é importante mostrar seu papel no processo histórico.

Em 1921, Walter Benjamin escreveu o ensaio "Zur Kritik der Gewalt" (Para uma Crítica da Violência), ${ }^{4}$ que aparece em inglês como "The Critique of Violence". Gewalt denota não apenas violência, mas também o conceito de poder, que dadas as

\footnotetext{
${ }^{4}$ BENJAMIN, W. Documentos de Cultura, Documentos de Barbárie, S. Paulo: USP, 1986, p. $160-175$.
} 
suas sinistras ambigüidades continua a ser um dos textos mais problemáticos da obra de Benjamin. Neste texto a semântica de Gewalt oscila constantemente entre esses dois pólos: violência e poder. Todo o ensaio então é construído sobre a ambigüidade da palavra Gewalt, onde a intenção de Benjamin é mostrar a origem do direito (e do Poder Judiciário) a partir do espírito da violência. Percebe-se que Benjamin fala sobre o direito (positivo), ou seja, a lei, que a todo o momento reafirma-se a si mesma, através da violência, revelando algo de podre nesta mesma lei. A decadência interna da lei é o fato de que o preceito legal é desprovido de legitimação, de que o próprio espaço do raciocínio jurídico dentro do qual prevalece o preceito legal é sustentado por uma dimensão de força, poder e violência que acabam por ocupar o lugar dos fundamentos que faltam. Raciocina corretamente Benjamin, negando a lei, que é fonte de um desequilíbrio e degeneração institucional crônico, quando se auto-reafirma no enunciado: “A lei é a lei!”. Benjamin ${ }^{5}$ distingue dois aspectos dessa dimensão da lei: a violência instauradora da lei (rechtsetzende Gewalt) e a violência mantenedora da lei (rechtserhaltende Gewalt). A violência instauradora da lei marca pela primeira vez a fronteira entre o que será considerado legal e ilegal, enquanto a violência mantenedora da lei serve exatamente para regular e manter as fronteiras entre os atos legais e ilegais. Benjamin dá a essa violência (que instaura e mantém o direito) o nome de violência mítica ("poder sangrento sobre a mera vida em nome da violência"), usando o conceito de mito para entender os efeitos de poder das representações. Esta violência seria digna de reprovação, pois instituindo um direito, poderia ser chamada de dominante; devendo ser rejeitado, todo poder mítico, o poder instituinte do direito, pode ser chamado de um poder que o homem põe (schaltende Gewalt). Para Benjamin, diga-se de passagem, a polícia representa uma espécie de mistura espectral dessas duas formas de violência; a polícia é o lugar em que a violência extralegal da qual depende estruturalmente o preceito legal manifesta-se da maneira mais clara; sua presença é fantasmagórica na vida dos Estados civilizados. No começo da lei, portanto, há um certo fora-da-lei, um certo real da violência que coincide com o próprio ato de instauração da lei: a verdade última sobre o império da lei é a de uma usurpação, e todo o pensamento político filosófico clássico repousa num desmentido desse violento ato de fundação, esclarece Žižek:

\footnotetext{
${ }^{5}$ SANTNER, E. A Alemanha de Schreber: uma História Secreta da Modernidade, Rio: JZE, 1997, p. 23.
} 
a violência ilegítima através da qual a lei se sustenta deve ser escondida a qualquer preço, pois essa ocultação é a condição positiva do funcionamento da lei: ela funciona na medida em que seus sujeitos são enganados, na medida em que vivenciam a autoridade da lei como 'autêntica e eterna', passando-lhes despercebida 'a verdade sobre a usurpação. ${ }^{6}$

Nietzsche $^{7}$ influencia fortemente Benjamin no que diz respeito a violência instauradora da lei:

O ato mais decisivo, entretanto, que o poder supremo pratica (...) é a instituição da $l e i$, a declaração imperativa do que figura em geral como permitido e justo a seus olhos, e do que figura como proibido, injusto: depois de haver instituído a lei, ele trata a violência e os atos caprichosos por parte dos indivíduos ou grupos inteiros como delitos contra a lei, como uma rebeldia contra o próprio poder supremo. (...) "Justo" e "injusto", por conseguinte, só existem depois da instituição da lei. (...) Falar em justo ou injusto em si é perfeitamente sem sentido. ${ }^{8}$

O estado de emergência ou de exceção (Ausnahmezustand) é inaugurado pela própria ordem legal, e não por qualquer ato criminoso perpetrado contra ela, diz Nietzsche. Ainda em 1921, Benjamin nega a lei, no entanto, não realiza a negação da negação:

...violência como "meio puro", isto é, como figura de uma paradoxal "medialidade sem fins": isto é, um meio que, permanecendo como tal, é considerado independentemente dos fins que persegue (...) É pura a violência que não se encontra numa relação de meio quanto a um fim, mas se mantém em relação com sua própria medialidade. ${ }^{9}$

Uma violência que desempenhe na história transformações profundas nas estruturas seculares da sociedade burguesa cristã, determinando o desaparecimento de

\footnotetext{
${ }^{6}$ ŽIŽEK, S. Eles não Sabem o que Fazem: O Sublime Objeto da Ideologia, Rio: JZE, 1992.

${ }^{7}$ NIETZSCHE, F. A Genealogia da Moral, Colecção de Filosofia e Ensaios, Lisboa, s/ data.

${ }^{8}$ Idem.

${ }^{9}$ AGAMBEN, 2004, p. 95 - 96.
} 
certos valores, rompendo com certos tipos de dominação e sentimentos e criando novas formas de relações entre os homens se expressa na ação política na rua; isso tudo é um movimento de mudança social e cultural, como diz Engels:

A violência desempenha na história um papel revolucionário; sabemos que ela é, também, para usar uma expressão de Marx, a parteira de toda a sociedade antiga, que traz em suas entranhas uma outra nova: que é ela um instrumento por meio do qual se faz efetiva a dinâmica social, fazendo saltar aos pedaços as formas políticas fossilizadas e mortas. ${ }^{10}$

Desta forma, é a leitura histórica, muitas vezes na atmosfera a-histórica como produtora do ato político que produz história, que permite assimilar revolução e violência numa sintonia dialética e interpretar esta última como uma fase ou síntese dialética neste processo histórico, necessária para a ruptura de estruturas sociais burguesas seculares. Já em 1940, neste movimento dialético, em suas teses sobre o conceito de história, o próprio Benjamin lembrou que a história, tal como ela veio se desenrolando até o presente, está impregnada de violência e de barbárie, isto porque tanto a história quanto o direito sempre foram concebidos como oficiais; e é exatamente por isso que o olhar do teórico do materialismo histórico não pode estar voltado para uma espécie de prolongamento natural dessa história, não promovendo a continuidade daquilo que essa história produziu; o olhar historiográfico tradicional que se limita ao "que realmente aconteceu", fazendo da história uma corrente fechada, linear e homogênea, já é, a priori, formalmente, o olhar "dos que venceram": vê a história como um contínuo fechado da "progressão" que levou à dominação atual, abstraindo ao mesmo tempo o que faltou na história, o que teve de ser negado para que se pudesse estabelecer o contínuo do "que realmente aconteceu". ${ }^{11}$ É por isso que Benjamin vai dizer que um espírito dialético, insiste em "escovar a história a contrapelo". ${ }^{2}$ Ainda sobre o conceito de história e sua crítica, Benjamin mostra que "o passado traz consigo um índice misterioso, que impele à redenção", ${ }^{13}$ e que a toda hora temos que nos

\footnotetext{
${ }^{10}$ ENGELS, F. Anti-Dühring, Rio: Paz e Terra, 1990, p. 161.

${ }_{11}$ ŽIŽEK, S. O Mais Sublime dos Histéricos - Hegel com Lacan (Les Plus Sublime Des Hysteriques - Hegel passe), Rio: JZE, 1991, p. 181.

${ }^{12}$ LÖWY, M. Walter Benjamin: Aviso de Incêndio - Uma Leitura das Teses "Sobre o Conceito de História", S. Paulo: Boitempo, 2005, p. 70.

${ }^{13}$ BENJAMIN, W. Magia e Técnica, Arte e Política: Ensaios sobre Literatura e História da Cultura, S. Paulo: Brasiliense, 1994, p. 223.
} 
perguntar com quem o investigador historicista estabelece uma relação de empatia. A resposta, diz Benjamin, é inequívoca: com o vencedor.

Nunca houve um monumento da cultura que não fosse também um monumento da barbárie. E, assim como a cultura não é isenta de barbárie, não o é, tampouco, o processo de transmissão da cultura. Por isso, na medida do possível, o materialismo histórico se desvia dela. Considera sua tarefa escovar a história a contrapelo. ${ }^{14}$

A luta de classes, que "um historiador educado por Marx jamais perde de vista, é uma luta pelas coisas brutas e materiais, sem as quais não existem as refinadas espirituais" "15, esclarece Benjamin. Esta luta hoje em dia não é somente de classes, mas de todos os grupos subalternos e oprimidos, que terão o legítimo direito de encontrar seus direitos na violência, seja ela "pura" ou "revolucionária". É interessante ainda, que Benjamin destaca a diferença entre a violência de um movimento revolucionário que tenta tomar o poder estatal e a violência de um movimento que, ao contrário, tenta destruir o poder do Estado rejeitando qualquer relação com a lei. Essa segunda forma de violência é "pura" ou "imediata", no sentido que não presta atenção a nada que seja externo, a nenhuma representação. Benjamin tenta entender positivamente esta violência em termos duma "violência divina": poder puro sobre a vida toda em nome dos vivos, exprimindo a própria vida fora da lei, na forma do vivo, nunca sendo um instrumento de execução sacra. ${ }^{16}$

O próprio Benjamin disse que "a tradição dos oprimidos nos ensina que o "estado de exceção" em que vivemos é na verdade a regra geral e que precisamos construir um conceito de história que corresponda a essa verdade". Nesse momento, percebemos que nossa tarefa é originar [criar] um verdadeiro [real] estado de exceção [emergência]. ${ }^{17}$ Nesta interpretação da história, o direito (não estatal) e a violência irão se movimentar também dialeticamente e não "puramente pura"; isso não significa, que a violência benjaminiana (pura/divina) deva ser descartada, pois se o conceito de história corresponde à verdade do estado de exceção, caberá não somente aos proletários a

\footnotetext{
${ }^{14}$ BENJAMIN, 1994, p. 225.

${ }^{15}$ Idem, p. 223.

${ }^{16}$ HARDT, M. \& NEGRI, A. O Trabalho de Dionisio - Para a Crítica ao Estado PósModerno, Juiz de Fora: UFJF, Pazulin, 2004, p. 171 - 172.

${ }^{17}$ BENJAMIN, 1994, p. 226.
} 
mudança, mas a todos os grupos subalternos, esta ruptura, inclusive aos intelectuais marginalizados, direcionando esta "violência divina" para criar um real estado de exceção benjaminiano.

\section{3. "Instante" ou "Tempo-de-agora"}

Nesta leitura, atenta à secularização e ao mesmo tempo à ruptura, as intensidades, não redutíveis à representação schmittiana, querem e desejam a eterna repetição do instante (perdido historicamente); é no "instante" (Nietzsche) que é feita a ruptura histórica pelas forças ativas, afirmando seus direitos políticos pela potência política na vontade de dar efetividade aos "direito(s) achado(s) na rua" (Roberto Lyra Filho) que não se encontram numa realidade dialética, necessitando ser "achados na violência" (J.C Galvão). Este sentido do instante é uma possibilidade de liberdade; este instante traz consigo potência, força, violência e ruptura; este instante é o "tempo-deagora" (Jetztzeit) benjaminiano, autêntico instante que interrompe o contínuo da história. ${ }^{18}$ É por isso que Proust vai em busca do tempo perdido, repetindo um instante que deveria ter acontecido, redescobrindo o tempo perdido, possibilitando a descoberta do tempo pela arte, de um "tempo puro" significando uma razão suficiente (o tempo a priori que não necessita do movimento empírico ou do excesso de razão), razão suficiente rompendo com o contínuo histórico. Aquilo que Benjamin denominou de "violência pura" coloca o movimento dialético em suspenso. A essência do tempo é ser puro, ou seja, não ter excesso de razão, para que o "homem de ação"19 possa romper com o continuo histórico no instante que a violência pura proporciona esse rompimento ou ruptura, feita pela "potência política", redescobrindo um tempo eternamente vivido no instante "a-historico", ${ }^{20}$ vivendo eternamente nos segundos da ação. Há instantes em que "de repente o tempo pára e o presente torna-se eternidade" (Dostoievski); só uma vez ou outra surge um "homem de exceção" (Buarque de Holanda), que possa criar um verdadeiro estado de exceção. Este (homem de exceção) precisa ser forte o bastante para resistir e, apesar de tudo, criar. O aqui e agora - "instante" ou "tempo-de-agora" - visto numa perspectiva político-filosófica é o rompimento com a história oficial dos

\footnotetext{
${ }^{18}$ LÖWY, M. Walter Benjamin: Aviso de Incêndio, S. Paulo: Boitempo, 2005, p. 15.

${ }^{19}$ NIETZSCHE, F. Escritos sobre História, Rio/ S. Paulo: PUC e Loyola, 2005, p. 76.

${ }^{20}$ Idem, p. 74.
} 
dominantes e conquistadores. Só em instantes de forte tensão é que os homens se encontram frente a frente com as forças subterrâneas que desmantelam sínteses:

... esses "instantes" representam o que há de mais importante e que todo o resto se anula diante de sua força. ${ }^{21}$

A essência do direito, da política e da história vive no tempo perdido que é redescoberto no eterno retorno político de captura do instante que deveria ter ocorrido e não ocorreu; esse tempo volta repetidamente para eternamente retornar a este instante e como forma da arte expressar-se na política rompendo com a história: o eterno retorno numa perspectiva político-filosófica, entendido através do tempo perdido, é redescoberto pelo "homem de ação". O "homem de ação" é sempre, segundo Goethe, ${ }^{22}$ despojado de escrúpulos, esquece tudo exceto a coisa que quer fazer, não conhece senão um direito, o direito daquele que vai agora nascer; possuindo uma energia selvagem nos olhos; grandes homens são possibilidades reais sempre presentes da existência humana, geram a cada instante as forças vivas do presente, redimindo o tempo pela "potência política" e criando uma ferida na ordem, abrindo para o presente uma multiplicidade de possibilidades; a vontade que liberta se insurge contra fatos consumados, fazendo sempre novas interpretações do passado.

Talvez fosse essa a vontade de Benjamin, no caminho de uma "história aberta". Não sendo o futuro "conhecido antecipadamente"; 23 a contrapartida da objetividade histórica a negação das forças subjetivas no curso da história, nos grandes acontecimentos, extraem do presente tudo o que ele tem de forte para somente depois interpretar o passado. No estudo das relações de força, qualquer período histórico que se considere é caracterizado por uma tensão entre aquilo que está morrendo e aquilo que está nascendo.

Sabemos hoje em dia que quando uma "revolução" não ocorre nasce o estudo das catástrofes; e a grande questão a ser levantada é pensar a ação política dos subalternos em tempos de catástrofes, onde todas as formas se "dissolvem" (Lukács); por isso, em momentos históricos de desespero a ação ou violência é "pura", "divina" (Benjamin). Nesta dialética de destruição e criação - dialética da violência, as formas

\footnotetext{
${ }^{21}$ BUARQUE DE HOLANDA, S. O Espírito e a Letra - Estudos de Crítica Literária I: 19021947, S. Paulo: Companhia das Letras, 1996, vol. 1, p. 239.

${ }^{22}$ GOETHE, J. W. Máximas e Reflexões, Lisboa: Guimarães, 1987, p. 68.

${ }^{23}$ LÖWY, M. Walter Benjamin: Aviso de Incêndio, S. Paulo: Boitempo, 2005, p. 149.
} 
de ação preservam ou destroem, encontrando um meio para outras formas de convivência.

$\mathrm{Na}$ nossa interpretação, seja a "teologia" de Benjamin ou a "vontade de potência" em Nietzsche, existe uma força que movimenta a história e ao mesmo tempo rompe com o contínuo histórico. Esta força está nos grupos subalternos e no estudo das relações de forças que estes grupos produzem frente ao poder soberano. A esta força estamos chamando de "potência política", ou seja: vontade de potência politizada, que não é metafísica, porque está atenta aos fatos concretos políticos e aos estudos empíricos das relações destas forças geradas pelos subalternos. A potência política é força de resistência contra grupos dominantes; a potência política escreve a história no "sentido contrário" trazendo as forças vivas do presente como potencialidade da diferença.

Acreditamos que a "revolução" não é mais dos proletários, mas de todos os subalternos, principalmente dos homens de ação que não se subordinam ao estatuto do proletário; houve uma adesão do movimento operário ao Estado burguês, a começar pelos sentimentos. O proletário não faz mais ruptura com a ordem burguesa, no entanto, deveríamos ficar atento às "novas formas de consciência social" (Žižek), aos leões que o Estado não consegue domar. É por isso que, numa importante passagem Nietzsche vai falar:

É preciso que se tenha de estabelecer à força o seu direito: antes disto não se faz uso algum dela [da dialética]. ${ }^{24}$

É nesse ponto exato que chegamos na "revolução" de Benjamin, momento em que o contínuo se rompe, aniquilando-se a textura da história prévia, a dos vencedores:

À primeira vista, essa posição de Benjamin é radicalmente antihegeliana: não é a dialética a versão mais requintada do evolucionismo, onde as próprias rupturas são incluídas no contínuo do progresso, em sua lógica inelutável? Provavelmente foi assim que o próprio Benjamin vivenciou sua postura: ele designou o ponto de ruptura do contínuo histórico como o da "dialética em suspenso", como a intromissão de uma

\footnotetext{
${ }^{24}$ NIETZSCHE, F. Crepúsculo dos Ídolos - ou como Filosofar com o Martelo, Rio: Relume Dumará, 2000, p. 23.
} 
repetição pura que punha entre parênteses o movimento progressivo da Aufhebung. ${ }^{25}$

A suspensão do movimento é então o momento-chave do movimento dialético, presente, fortemente, no anti-evolucionismo radical de Hegel: o "nada", a negatividade absoluta que impulsiona para diante o movimento dialético. ${ }^{26} \mathrm{Em}$ todo caso, direito e violência estão hoje na situação de não mais poderem fugir a esta leitura políticofilosófica da história com seu movimento, proporcionado pela vontade afirmativa de potência como forma de criar uma nova política como arte do impossível.

\section{Conclusão}

Interpretar positivamente a violência divina benjaminiana (1921) numa perspectiva histórica, ou seja, junto com o real estado de exceção benjaminiano (1940) é tarefa de todo intelectual comprometido com as forças destrutivas da "segunda natureza em excesso", exatamente para possibilitar "que esta cebola seja descascada e comida”. É importante não tratar esta violência como algo inferior ou de um fenômeno próprio da história do fascismo. Esta violência é a única forma dos subalternos "poderem afrontar a arrogância, a impunidade e o saqueamento corsário do Estado realizado pelas elites políticas, industriais e financeiras do país, que estão mal acostumadas a serem protegidas pelo Estado à custa da predação daqueles grupos". ${ }^{27}$

A estes mesmos grupos subalternos, numa sociedade secular hierarquicamente dividida em classes, a estratificação social e política não coloca outra opção que não pegar em armas, realizar assaltos e assassinatos. Estes grupos marginalizados movimentam dialeticamente o direito na prática, exercendo uma forma de contra-poder face aos dispositivos instituídos pelo poder, mostrando que este ato violento é um legítimo direito político e está bem longe do conceito de barbárie. Como enfatizou Adorno, a tentativa de superar a barbárie é primordial para a sobrevivência da

\footnotetext{
${ }^{25}$ ŽIŽEK, S. O Mais Sublime dos Histéricos - Hegel com Lacan (Les Plus Sublime Des Hysteriques - Hegel passe), Rio: JZE, 1991, p. 186.

${ }^{26}$ Idem.

${ }^{27}$ BIRMAN, J. Mal-estar na Atualidade: a Psicanálise e as Novas Formas de Subjetivação, Rio: Civilização Brasileira, 2003, p. 284 - 285.
} 
humanidade, ${ }^{28}$ no entanto, é preciso ficar atento ao discurso oficial que tenta a cada dia, principalmente, através da mídia, confundir as massas, na mistura destes conceitos: violência e barbárie. A violência pode ser um sintoma de barbárie, mas não precisa necessariamente sê-lo; diz Adorno:

\begin{abstract}
Em circunstâncias em que a violência conduz inclusive a situações bem constrangedoras em contextos transparentes para a geração de condições humanas mais dignas, a violência não pode sem mais nem menos ser condenada a barbárie. ${ }^{29}$
\end{abstract}

Não constitui barbárie a ação dos movimentos sociais, grupos subalternos, nem mesmo a ação das consideradas "organizações criminosas", que usam muitas vezes da violência política (até mesmo inconscientemente numa "violência pura") baseada em considerações racionais, através de uma razão sensível, ainda que rompam os limites da legalidade. No entanto, é barbárie, por outro lado, a atuação mortífera da polícia política na "segunda natureza", legitimada por um sistema de justiça fascista.

Em momentos como esse, de acentuado antagonismo social, o que há de podre na lei é revelado por um excesso, seja numa "democracia" ou num "totalitarismo", onde a política é missionária ou secular. É como se a força performativa pertinente, em algum nível, a todas as instituições e aos fatos sociais que elas patrocinam na segunda natureza, começasse a vazar para fora de seu espaço "normalmente" circunscrito e a dissolver a capacidade da instituição de fornecer um contexto crível de realidade significativa. Em momentos como esse, a autoridade revela-se fascista, incapaz de esquecer e incapaz primordialmente de recalcar a dimensão pulsional da função simbólica, que se expande e transborda num “estado de exceção schmittiano”.

\footnotetext{
${ }^{28}$ ADORNO, T. W. Educação e Emancipação, Rio: Paz e Terra, 1995, p. 155 - 168.

${ }^{29}$ Idem, p. 159.
} 


\section{Referências}

ADORNO, T.W. \& HORKHEIMER, M. Dialética do Esclarecimento: fragmentos filosóficos. Trad. Guido Antonio de Almeida. Rio de Janeiro: Jorge Zahar Editor, 1985. AGAMBEN, G. Estado de Exceção. Trad. Iraci D. Poleti. São Paulo: Boitempo, 2004. BENJAMIN, W. Magia e Técnica, Arte e Política: Ensaios sobre Literatura e História da Cultura. Trad. Sérgio Paulo Rouanet. São Paulo: Brasiliense, 1994.

Crítica da Violência - Crítica do Poder. (1921) Trad. Willi Bolle. In Documentos de Cultura, Documentos de Barbárie. São Paulo: USP, 1986.

BIRMAN, J. Mal-estar na Atualidade: a Psicanálise $e$ as Novas Formas de Subjetivação, Rio de Janeiro: Civilização Brasileira, 2003.

BUARQUE DE HOLANDA, S. O Espírito e a Letra - Estudos de Crítica Literária I: 1902-1947. São Paulo: Companhia das Letras, 1996, vol. 1.

CUNHA, E. R. P. Os Sertões - Campanha de Canudos, Brasília: UnB, 1963.

ENGELS, F. Anti-Dühring. Rio de Janeiro: Paz e Terra, 1990.

GALVÃO JR., J.C. Dialética da Violência e Relações de Força. Rio de Janeiro: NPL, 2007.

O Guardião da Fé. Rio de Janeiro: NPL, 2008.

GOETHE, J. W. Máximas e Reflexões, Lisboa: Guimarães, 1987.

GRASS, G. Nas Peles da Cebola. Trad. Marcelo Backes. Rio de Janeiro / São Paulo: Record, 2007.

HARDT, M. \& NEGRI, A. O Trabalho de Dionisio. Trad. Marcello Lino. Juiz de Fora: UFJF e Pazulin, 2004.

LÖWY, M. Walter Benjamin: Aviso de Incêndio - Uma Leitura das Teses "Sobre o Conceito de História”. Trad. Wanda Nogueira Caldeira Brant. Trad. das teses: Jeanne Marie Gagnebin e Marcos Lutz Muller. São Paulo: Boitempo, 2005.

LUKÁCS, G. História e Consciência de Classe. Trad. Rodnei Nascimento. São Paulo: Martins Fontes, 2003.

NIETZSCHE, F. Escritos sobre História. Trad. Noéli Correia Sobrinho. São Paulo: Loyola, 2005.

Crepúsculo dos Ídolos - ou como Filosofar com o Martelo. Trad. Marco Antonio Casa Nova. Rio de Janeiro: Relume Dumará, 2000. 
A Genealogia da Moral. Trad. Carlos José de Meneses. Lisboa: Guimarães, s/ data.

SANTNER, E. L. A Alemanha de Schreber: uma História Secreta da Modernidade. Trad. Vera Ribeiro. Rio de Janeiro: JZE, 1997.

SCHMITT, C. O Leviatã na Teoria do Estado de Thomas Hobbes - Sentido e Fracasso de um Símbolo Político. (1938) Trad. Cristiana Pessoa \& João C. Galvão Jr. In GALVÃO JR. J.C. Leviathan Cibernético - da quebra das máquinas ao Leviathan cibernético (Manifesto I). Rio de Janeiro: NPL, 2008.

ŽIŽEK, S. O Mais Sublime dos Histéricos - Hegel com Lacan (Les Plus Sublime Des Hysteriques - Hegel passe). Trad. Vera Ribeiro. Rio de Janeiro: JZE, 1991. 